\title{
Saberes descolonizados e uma nova historiografia para discutir a Nakba
}

RÔmulo Silveira Monte

MISLEH, S. Al Nakba: um estudo sobre a catástrofe palestina. São Paulo: Sundermann, 2017.

Em 04 de dezembro de 2017, meses após o lançamento de "Al Nakba: um estudo sobre a catástrofe palestina", o presidente dos Estados Unidos, Donald Trump, anunciou o reconhecimento de Jerusalém como capital do Estado de Israel por parte do governo norte-americano e que estaria autorizando a transferência da embaixada americana de Tel Aviv para Jerusalém (LIMA, 2017). Israel reivindica o reconhecimento de Jerusalém como sua capital desde 1967, embora a Organização das Nações Unidas (ONU) não o faça. Tal reivindicação é expressão do plano sionista de ocupação da Palestina, descrito pela pesquisadora Soraya Misleh em seu livro e constitui parte de um conflito que se estende há muitos anos.

Jornalista de nacionalidade palestino-brasileira, atualmente doutoranda em Estudos Árabes pela Universidade de São Paulo, Soraya Misleh publicou recentemente o livro que resultou do seu estudo sobre o vilarejo de Qaqun, inspirada pelas histórias de seu pai, um sobrevivente da expulsão de habitantes palestinos desse vilarejo, ocorrida em 1948. A autora ressalta a importância de conhecer e compreender os diversos aspectos que constituem a história do conflito na Palestina, entre eles o plano de limpeza étnica empreendido pelas forças sionistas. Para tanto, apresenta o trabalho dos "novos historiadores" que trouxeram à tona um contraponto da história oficial do êxodo voluntário, o qual diz que

\section{Rômulo Silveira Monte}

Estudante de graduação do curso de Ciências Sociais da Universidade Estadual do Ceará e integrante do Programa de Educação Tutorial do referido curso (PET - Ciências Sociais - UECE). E-mail: romulocs2016@gmail.com 
os palestinos migraram de suas terras por orientação das próprias lideranças, mas que, apesar de seus esforços, foram invisibilizados.

Dividida em duas partes, a obra destina a primeira a um apanhado de processos históricos e à elucidação de conceitos sobre a formação do "Estado judeu". A segunda parte dá voz à memória coletiva de sobreviventes da Nakba, tendo como recorte o estudo de caso de Qaqun. Essa divisão confere ao texto maior facilidade de compreensão, pois situa o leitor em meio aos conceitos, apresentando-os de forma sistemática. Ademais, o texto expõe a história da ocupação israelense por um ponto de vista pouco conhecido, contando com testemunhos de três nativos palestinos, mapas, fotos e documentos que ilustram o processo de expulsão massiva de nativos de grande parte da região da Palestina.

Enquanto para as forças sionistas a conquista de vasto território em 1948 representa a celebração da independência, o fato adquire significado divergente para a população árabe que ali residia até o momento. A expressão "nakba" significa catástrofe e é empregada pelos árabes para se referir à criação do Estado de Israel. Apoiando-se em historiadores como 'Arif al 'Arif, Nur Masalha e Ilan Pappé, entre outros que compõem uma corrente teórica contra-hegemônica, a autora sustenta a tese de que o plano sionista levou à "destruição da Palestina histórica e limpeza étnica do povo que a habitava" (MASALHA, 1992 apud MISLEH, 2017, p. 20), fragmentando toda uma sociedade. Embora a história oficial israelense comumente negue a nakba, para Clemesha (apud MISLEH, 2017), a nova historiografia conseguiu abalar o discurso dominante, chegando a questionar a manipulação da "fé judaica" em ideologia laica que reinterpreta os textos bíblicos em prol da aplicação de seus planos (MASALHA apud MISLEH, 2017 p. 21 - 20).

O "sionismo moderno", segundo Misleh (2017), inspira-se no "protonacionalismo judeu", que contou com um movimento de intelectuais da década de 1850, entre eles está Moses Hess, um dos "pioneiros em escrever sobre o nacionalismo judeu" e que defendia a "regeneração nacional de Israel" (MISLEH, 2017, p. 23), justificada por um "caráter nacional do judaísmo". Nesse movimento, encontram-se os precedentes históricos para o que viria a se tornar o "sionismo", termo inventado pelo judeu Nathan 
Birbaum (MISLEH, 2017). O movimento contou ainda com Theodor Herlz, que afirmava não haver esperança para a assimilação dos descendentes judeus a outros lugares que não fosse um Estado judeu, o que justificaria a tentativa de "restaurar" a nação judaica. Assim, mobilizou-se para conseguir o apoio das elites judaicas e de governantes europeus.

Dessa forma, ainda segundo Misleh (2017), o sionismo buscou descaracterizar os nativos da Palestina, manifestando desprezo pelos árabes e considerando-os um "não povo", chegando a concluir que aquela terra estava desocupada. Embora reivindicassem uma raiz, lançaram-se em um projeto de colonização eurocêntrica, se dispondo como espécie de trincheira avançada da Europa. Por conseguinte, a Grã-Bretanha se manteve em apoio ao projeto sionista, pois conservava interesses estratégicos naquela região, que serve de "ponte terrestre" entre Ásia e África, garantindo, assim, que não se formasse uma nova configuração geopolítica alheia aos seus interesses. Em acordo aos interesses comuns, "lordes e banqueiros ingleses patrocinaram pessoalmente a imigração judaica para a Palestina" (MISLEH, 2017, p. 39).

O início da imigração, no final do século XIX, em princípio, não chegou a configurar grandes conflitos. A ela, seguiram-se duas grandes ondas migratórias, uma em 1882 e outra de 1903 a 1914. O objetivo dos assentamentos estabelecidos era "obter o domínio da terra e do trabalho", primeiramente empregando a mão de obra dos habitantes locais de maneira precarizada e posteriormente se desvencilhando dessa força de trabalho, com o fim de minar as condições de vida dos habitantes nativos. Em 1928, o mandato britânico propôs uma estrutura parlamentar com número paritário de representações, mas os palestinos, que até então eram maioria (entre $80 \%$ e $90 \%$ da população), recusaram tal proposta. Com o aumento da imigração sionista, os palestinos voltaram atrás, mas, dessa vez, o projeto foi recusado pelos sionistas.

Em 1936, eclodiu uma das revoltas mais expressivas desse período - uma greve geral que durou seis meses, acompanhada de levantes palestinos, os quais acabaram reprimidos com auxílio do mandato britânico, produzindo uma situação ainda mais fragilizada para as forças de resistência nativas. Com o apoio britânico, 
foram construídas "redes de estradas para conectar os principais assentamentos judeus, o que viria a constituir a infraestrutura básica de sua economia" (MISLEH, 2017, p. 44).

Dedicados à Declaração Balfour, que garantia o apoio da Grã-Bretanha à criação de um Estado judeu na Palestina, os sionistas buscaram ao máximo fazê-la ser cumprida. No entanto, com a limitação que o mandato britânico estabeleceu à imigração para a região em 1939, os sionistas se viram na necessidade de repensar os seus planos de ocupação e, como demonstra a autora, "realizaram uma conferência em maio de 1942" nos Estados Unidos, a fim de "estabelecer aliança com a potência emergente". Na ocasião, teriam declarado "o objetivo de criar um estado judeu em toda a palestina"(MISLEH, 2017, p. 45).

A escritora segue apresentando uma grande quantidade de fatos históricos e de aparato teórico de maneira concisa. Entre os fatos mostrados, está o planejamento estratégico de Israel, que, em princípio, mapeia vilas e busca informações sobre os habitantes das regiões, como religião, idade, se suas famílias haviam perdido membros ou se há feridos em decorrência da revolta de 1936 (este último seria um dos fatores para classificar a hostilidade das vilas ao projeto sionista). Tudo isso, além de servir de base para o planejamento militar, serviria também para os planos de transferência dos nativos e de ocupação pelos colonos.

Valendo-se de bibliografia pouco traduzida para o português, Misleh (2017) dá continuidade à exposição de autores que oferecem uma nova visão ou uma nova versão do que a história oficial costuma apresentar. Em Masalha (apud MISLEH, 2017, p.49), o que se costuma chamar de transferência deu-se de forma previamente planejada e incluía práticas de limpeza étnica, "expropriação" e "assédios", de modo a impelir a partida dos habitantes, pois essa seria uma "pré-condição para a realização do projeto sionista".

Neste ponto, a autora estabelece um debate entre Benny Morris, Pappé e Masalha. O primeiro historiador afirma que a transferência é um projeto que tomou tal proporção, devido à não aceitação dos árabes em dividir o território, provocando a guerra que alcançou seu ápice em 1948. Pappé e Masalha discordam dessa versão, tratando o fenômeno da transferência como algo arquitetado pelos sionistas, o que ilustram com a exposição de seus planos. 
Na geopolítica mundial, surgiu um elemento que influenciou diretamente a região: a ocorrência da Segunda Guerra Mundial entre 1939 e 1945. O período representou certo desenvolvimento econômico para a Palestina, porém também provocou mudanças significativas na organização militar sionista e na imigração judaica, por conta dos ataques sofridos por judeus pelos nazistas, ocorridos apesar da restrição à entrada na Palestina e de uma espécie de triagem que favorecia aqueles que tivessem "boa forma física" e a "inclinação política adequada" (MISLEH, 2017. p. 52). Pappé (apud MISLEH, 2017) declara que não houve grandes esforços sionistas para livrar os judeus do horror nazista, pois, segundo ele, o objetivo naquele momento era a manutenção do projeto de estado.

Em 1947, a Grã-Bretanha passa a responsabilidade de mediação no conflito para a ONU, que cria um comitê específico para a questão, o United Nations Special Committee on Palestine (Unscop). O comitê resolve aprovar a resolução no 181 que "dividia a palestina em oito partes, sendo três ao futuro estado judeu, quatro ao estado árabe [...] e Jerusalém sob administração internacional [...]" (MISLEH, 2017, p. 56). Para os autores citados na obra, essa divisão era a "receita para uma tragédia", pois não houve a preocupação de incluir medidas que impedissem o Estado judeu de avançar com o plano de tomar a totalidade do território. Assim, foram postos em prática planos de "limpeza étnica", que se caracterizam pela tentativa de homogeneização étnica e de "remoção forçada" de uma população.

Misleh (2017) retoma Pappé para expor os quatro planos principais elaborados para lançar as ofensivas sobre os palestinos, mas confere maior atenção ao Plano Dalet, o mais decisivo. O plano foi posto em prática a partir de 10 de março de 1948 e durou seis meses. Independentemente da colaboração dos habitantes, o plano previa a sua "expulsão sistemática e total", contando com informações privilegiadas e mapas detalhando a forma de ação durante os ataques às vilas, datas prévias para os ataques e a força de três organizações paramilitares: a Gangue Stern, Irgun e Haganah, que, ainda por cima, encontraram a resistência muito enfraquecida, devido ao embargo britânico que impediu que os árabes se armassem. 
Após ter exposto os conceitos, a autora continua com os relatos de três sobreviventes da vila de Qaqun, geralmente com o sentimento de pertencimento e identidade que os remete ao local de origem. São eles Tawfiq Abder Rahim, Abder Raouf e Abdul Qader yousef Al- Hafi. A vila foi um dos alvos do Plano Dalet, teve três lados cercados e foi atacada para que as pessoas se retirassem à força. Pappé (apud MISLEH, 2017, p. 67) ressalta que existem registros militares suficientes que descrevem como agiram na ocupação de Qaqun, registrando, inclusive, indícios de execuções de soldados iraquianos e um caso de estupro.

Os sobreviventes narram suas lembranças em relação ao modo de vida, marcado pela simplicidade e predominantemente agrícola, com relativo conforto e paz. Como conta Abder Raouf, "90\% dos aldeões viviam razoavelmente, sem queixas porque a terra era fértil" (MISLEH, 2017, p 71). Abder Rahim ressalta o intercâmbio de mercadorias entre os habitantes: "cultivávamos legumes, verduras, frutas e nos centros tinha comércio e indústria. Um completava o outro" (MISLEH, 2017, p. 73). No que se refere ao evento da tomada da aldeia, em junho de 1948, as falas recebem o teor denso de vivências traumáticas. Assim, descreve Abder Raouf: "eu vi mulheres que a bomba explodiu, eu vi gente com barriga tudo aberta" (MISLEH, 2017, p. 81).

A operação deixou centenas de mortos e desabrigados. Após isso, Misleh (2017) reitera a invisibilização que a história palestina sofre e como o Estado de Israel tem parte nesse processo, tentando apagar os vestígios de palestinos na região. Segundo ela, muitos vilarejos deram lugar a bosques e tiveram a paisagem fortemente alterada; foram criados comitês para renomear o território em hebraico com o objetivo de apagar a influência árabe sobre a região.

Em síntese, a autora reforça a tese de que a aldeia de Qaqun sofreu um violento processo de expropriação, tendo sido inserida no Plano Dalet (apresentado integralmente em anexo do livro). Esse plano autorizava investidas militares e a destruição de aldeias palestinas, apesar das ações estarem previstas como "retaliação" - o que o plano não configura como justificativa plausível para ações de limpeza étnica. A obra oferece leitura fluida, apesar 
de densa. A autora não se fecha a pequenos grupos de intelectuais; pelo contrário, em seu esforço de construir um trabalho que rediscuta a questão, ela traz várias contribuições de historiadores pouco conhecidos e pouco traduzidos para o português. Se não foi "pretensão" da pesquisadora "esgotar o tema", sua pesquisa faz parte de uma séria e importante bibliografia.

\section{REFERÊNCIAS}

LIMA, J. A. Trump reconhece Jerusalém como capital de Israel: o que isso significa. Carta Capital, [online], 06 dez. 2017. Internacional. Disponível em: <https://www.cartacapital.com.br/internacional/trump-reconhecejerusalem-como-capital-de-israel-o-que-isso-significa>. Acesso em: 17 jan. 2018. 